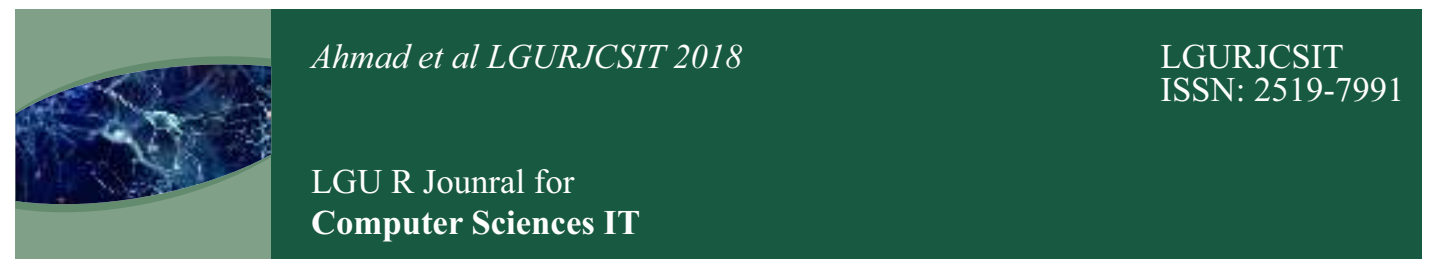

Vol. 2 Issue 3, July - September 2018

\title{
Statistical Power Profiling of Various Network Switches
}

Waqas Ahmad', waqasahmad@lgu.edu.pk, Awais Salman Qazi ${ }^{1}$, awais.salman@1gu.edu.pk Department of Computer Science\& IT, Lahore Garrison University, Lahore, 54000, Pakistan

\begin{abstract}
In the present century there is an expansion in the use of telecommunication network services, because many organizations and business firms do not compromise on networking services, therefore this efficiency of networking services can be achieved only if there are reliable and proficient networking components. To provide exemplary networking services it is necessary to know what are the parameters for networking components. A standout amongst the most vital parameters is the vitality utilization or energy utilization of networking components. Subsequently, there is a need for power profiling of the network switches. Power usage of different kinds of switches, under various load scenarios are tested and recorded. The tool that we have used in this research paper to measure the power usage factor of various switches is emonpi.
\end{abstract}

Keywords-Power Profiling, Switches, Network Components, Power Usage

\section{INTRODUCTION}

Recently, network services in a telecommunication sector have great importance. Companies, organizations, business firms, institutions whether small or large do not prefer slow and outdated network service. Everyone is looking for a nonstop and exceptional network service. Due to this increasing demand of nonstop network service, the need of huge access/data rates came into being. Nowadays fastest data rates are in use. With these faster data rates, the internet speed and performance is rapidly improving day by day. High data rate is directly proportional to the network service. Data rate is the ability to transfer bits per second from one place to another. Therefore, high data rate helps in making network performance better. Network performance can also be maximized if we use more number of switches in a network. Switch is also a network component. Every network component in a communication network has its own duties. The responsibility of switch is to pass the traffic from one node to another in a telecommunication network. Every device or component has its specific power consumption, because it works with the input of electricity.
Some components consume more power as compared to the others. Network companies must be aware of the power usage factor of various networking components. Because if they ignore and do not give attention to the power usage of components, then they have to indulge themselves in submitting huge electricity bills of their organizations. So it is necessary to have a proper energy management of networking components. As there are many developments in the field of power sector, it principally brings growth in the use of computational resources as well. The more we will use these resources, power usage will be increased. Many organizations prefer to make large data centers in which maximum data can be stored. Organizations like Google, Microsoft, IBM, Siemens, Nokia, Samsung, HTC, LG, Huawei etc. have big data centers with large number of networking componentsintegrated with various servers, that makes possible of storing tremendous amount of data. These data centers are consuming huge power everyday just for the sake of their customer needs and to process the information on daily basis. Data center is a heart of an IT industry. Power usage must be taken into account and its profiling must 
be done so as to control the budgeting of IT industry $[1,2]$. Power consumption of data centers calculated in year 2012 was approximately about $270 \mathrm{TW} / \mathrm{h}$, if compare this with the world's power consumption, we find out that it is only $2 \%$ consumption. New York times has also published a report in year 2012 which stated that the power consumption is equal to $29.9 \mathrm{GW} / \mathrm{h}$. This consumption is almost equal to the power generation of 30 nuclear plants. But the power consumption of data centers is increasing at a high rate per year. It is increasing $4.3 \%$ annually, which is an alarming situation for all industries and organizations. Therefore, power profiling has been one of the latest research areas for many scientists. Researchers are continuously doing research on finding a better solution to overcome the access of power consumption. Power profiling is human friendly and system friendly technique that monitors power consumption properties of computational resources [3]. In this research paper we have performed power profiling by putting load on every important part of the computer and this load is being monitored by power monitoring tool, then all the data which has been collected by the monitoring tool is made available for analysis. The main aim in power profiling is to keep the quality of service intact, while monitoring the energy consumption of network components. There are two types of power monitoring tools i.e. Software tools and Hardware tools. Most common tools used to check the behavior of real world process or environment are the software tools. These tools are also known as simulators [6].

\section{LITERATURE REVIEW}

Already done work relating to this topic is introduced. Below in the references section, if we take a look on the reference number [7], those authors also worked on power profiling of various network components in an operational phase. They did power profiling of heterogeneous network both in residential and commercial networks, keeping in mind the more network components. They found out that the energy consumption of network components has an increment of 5\% from year 2009 to 2017 . In another research paper i.e. [4], the authors have done research on specifically network switches, finding the power consumption of network switches. Network switches are the integral part of the whole communication network. These switches are busy all the time, so knowing the power consumption of switches can help in maintaining the efficiency of communication network. Authors did not rely only on a single network switch, in fact they have studied the power consumption of various switches of different brands, so as to achieve a reliable understanding. They found out that if a network switch has a higher processing ability, it will consume more energy as compared to a switch that is a bit weak in processing. Nowadays Cisco switches are considered more safe and reliable and with more powerful processing capacity. In the research paper number [5], authors have put their effort on a sensor network to determine the energy consumption. An external traffic load has been inserted on to this sensor network and power consumption of network elements has been measured by using the tool named EPUMS along with the bit rate. They have done research to see the power consumption of routers and found that the router operating at maximum clock rate consumes more power than the others. In the reference number [8], power management of various network devices in local area network are considered for research. During the normal communication activity, network devices for power management cannot be examined, therefore during the low traffic the components that are being attached with the switches are turned off for a while and then examined. Authors obtained reasonable result and saved reasonable amount of energy after performing this activity. This clearly shows that turning off network components may save power consumption of any network. In [9] reference, authors did their research on network devices like hubs, switches (edge \& core), routers and wireless access points and calculated the energy consumption in two different scenarios i.e. standalone and data center. The different thing in this research was a proportionality index proposed by authors that can be used to measure the power consumption of different network components. Similarly, in reference [10], authors used power estimator tool named BITWATTS that is used to measure the energy consumption at virtual machine level.

\section{METHODOLOGY USED}

We have to calculate the real power of any component or system of network. Real power's formula is little bit different as compared to the simple power formula. Real power is calculated as follows: 
Real Power $=$ Apparent Power $\times \operatorname{Cos} \theta$ (1)

Real power is the sum of instantaneous powers calculated at different samples divided by the number of samples. Therefore, mathematically real power can be calculated as follows:

$\mathrm{N}=$ no. of samples

I-power $=$ I-voltage $\times$ I-current

Sum-I-power $+=$ I-power

Real Power $=\{$ Sum-I-power $\} /\{$ no. of samples $\}$ (2)

Similarly, the experimental approach that we have used in our research can be better explained with the help of flow chart. Because flow chart describes the process step wise and it is easy to understand. Following flow chart shows what we have done for this research paper.

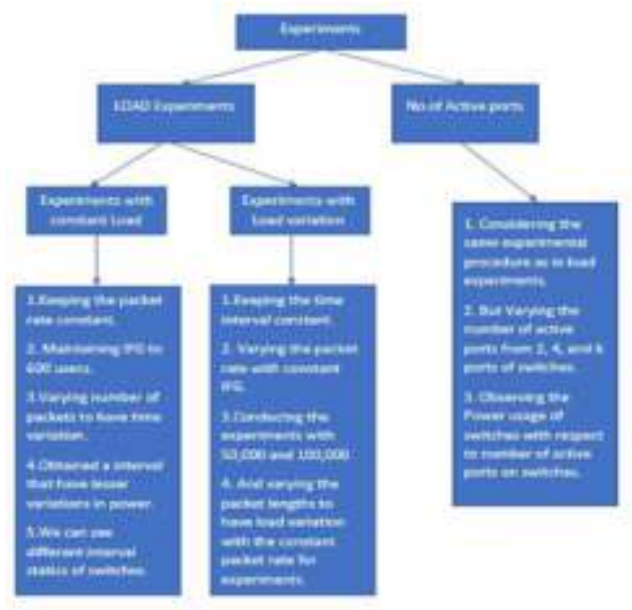

Figure 1. Experimental Procedures

\subsection{Mathematical Equations}

In this research paper the main objective of our research is to create a power profile for the network components, therefore we must know how to calculate the power. The mathematical formula for this is shown below:

Power $\{\mathrm{P}\}=$ Voltage $\{\mathrm{V}\} \times$ Current $\{\mathrm{I}\}$ $\mathrm{P}=\mathrm{V} \times \mathrm{I}(3)$

Similarly, formula for energy will be: Energy $(\mathrm{E})=$ Power $(\mathrm{P}) *$ Time $(\mathrm{T})$ $\mathrm{E}=\mathrm{P} \times \mathrm{T}(4)$

The standard international (SI) units for power and energy are Watts and Joules respectively. Power is defined as the rate at which work is done, while energy is defined as a capacity of physical system to perform work.

\section{STATISTICAL ANALYSIS OF SWITCHES}

At the start, experiments have been conducted on three different switches i.e. Cisco2950, Cisco-3560 and Netgear GS-724T. Different time intervals were taken, starting from 30 seconds to 210 seconds with a gap of 30 seconds each. Initially after some experiments we have seen an interval at which there was very little power variation. So we decided to use that interval and put traffic load onto three different switches and then tried to get the power consumption of these switches. Traffic load must be constant for all these switches. Data packets used for these switches were changed from 50,000 to 350,000 and time interval varied from 30 seconds to 210 seconds. Results obtained from these switches are summarized in the table below. Table 1 shows the power variations of different switches, and it has been observed that latest time has the minimum value of power variation in all of the switches. Therefore, maximum time value is the most suitable time period at which traffic load can be generated in order to observe the power usage of three switches.

Table 1. Statistics of Switches at Different Time Intervals

\begin{tabular}{|c|c|c|c|c|c|c|}
\hline SWITCH & $\begin{array}{l}\begin{array}{l}\text { TIME } \\
(\mathrm{sec})\end{array} \\
\end{array}$ & $\begin{array}{l}\text { AVERAGE } \\
\text { POWER }\end{array}$ & $\begin{array}{l}\text { MINIMUM } \\
\text { POWER }\end{array}$ & $\begin{array}{l}\text { MAXIMUM } \\
\text { POWER }\end{array}$ & $\begin{array}{l}\text { VARIATION } \\
\text { IN POWER }\end{array}$ & $\begin{array}{l}\text { STANDARDD } \\
\text { DEVIATION }\end{array}$ \\
\hline \multirow{7}{*}{$\begin{array}{l}\text { CISCO } \\
2950\end{array}$} & 30 & 63.1 & 50.02 & 78 & 45.33 & 6.73 \\
\hline & 60 & 63.5 & 54.67 & 70.35 & 16.99 & 4.12 \\
\hline & 90 & 63.9 & 59.15 & 68.50 & 4.92 & 2.21 \\
\hline & 120 & 64.1 & 60.97 & 67.08 & 2.75 & 1.65 \\
\hline & 150 & 63.8 & 60.53 & 67.55 & 3.22 & 1.79 \\
\hline & 180 & 63.7 & 60.12 & 66.8 & 1.80 & 1.34 \\
\hline & 210 & 63.5 & 61.83 & 66.08 & 0.98 & 0.99 \\
\hline \multirow{7}{*}{$\begin{array}{l}\text { CISCO } \\
35600\end{array}$} & 30 & 61.7 & 48.88 & 74.47 & 37 & 6.08 \\
\hline & 60 & 62.6 & 56.13 & 69.03 & 13.17 & 3.62 \\
\hline & 90 & 62.4 & 57.61 & 67,48 & 5.71 & 2.39 \\
\hline & 120 & 62.3 & 59.60 & 64.92 & 1.86 & 1.36 \\
\hline & 150 & 62.0 & 59.64 & 65.23 & 1.93 & 1.39 \\
\hline & 180 & 62.3 & 59.60 & 65.41 & 2.11 & 1.45 \\
\hline & 210 & 62.2 & 60.07 & 64.48 & 1.14 & 1.069 \\
\hline \multirow{7}{*}{$\begin{array}{l}\text { NETGEAR } \\
\text { GS 724T }\end{array}$} & 30 & 54.9 & 44.8 & 66.25 & 29.16 & 5.477 \\
\hline & 60 & 55.9 & 46.93 & 65.58 & 25.86 & 5.08 \\
\hline & 90 & 56.0 & 50.66 & 62.02 & 9.93 & 3.15 \\
\hline & 120 & 55.7 & 53.52 & 57.91 & 1.21 & 1.10 \\
\hline & 150 & 55.7 & 52.3 & 60.33 & 4.98 & 2.23 \\
\hline & 180 & 55.6 & 52.11 & 58.45 & 3.50 & 1.87 \\
\hline & 210 & 56.1 & 53.99 & 57.95 & 0.87 & 0.93 \\
\hline
\end{tabular}


Table 2 shows the power profiling of three switches when maximum load with size of 1470 bytes have applied on them. The link speed on each switch is constant i.e. 100Mbps.

Table 2.Power Profiles of Switches with Maximum Load Size 1470 bytes

\begin{tabular}{|c|c|c|c|c|c|c|}
\hline SWITCH & $\begin{array}{l}\text { LOAD } \\
\text { (Mbps) }\end{array}$ & $\begin{array}{l}\text { AVG } \\
\text { POWER }\end{array}$ & $\begin{array}{l}\text { MIN } \\
\text { POWER }\end{array}$ & $\begin{array}{l}\text { MAX } \\
\text { POWER }\end{array}$ & $\begin{array}{l}\text { STANDARD } \\
\text { DEVIATION }\end{array}$ & $\begin{array}{l}\text { INTERVAL } \\
(95 \%)\end{array}$ \\
\hline \multirow{5}{*}{ CISCO 2950} & 97.1 & 68.9 & 48.8 & 89.2 & 10.02 & 4.39 \\
\hline & 53.2 & 67.4 & 44.73 & 98.8 & 11.35 & 4.97 \\
\hline & 36.6 & 62.9 & 50.76 & 73.53 & 6.75 & 2.96 \\
\hline & 22.5 & 62.5 & 54.28 & 68.58 & 4.46 & 1.95 \\
\hline & 12.7 & 62.3 & 57.64 & 69.85 & 3.96 & 1.73 \\
\hline \multirow{5}{*}{ CISCO 3560} & 97.1 & 68.4 & 33 & 89.33 & 14.09 & 6.17 \\
\hline & 53.2 & 59.5 & 37.46 & 89.6 & 14.07 & 6.16 \\
\hline & 36.6 & 58.5 & 53.96 & 73.36 & 4.03 & 1.77 \\
\hline & 22.5 & 58.5 & 54.25 & 68.04 & 3.25 & 1.42 \\
\hline & 12.7 & 58.4 & 54 & 65.84 & 3.85 & 1.68 \\
\hline \multirow{5}{*}{ GS 724T } & 97.1 & 62 & $\begin{array}{ll}18.2 \\
\end{array}$ & 99.2 & 26.39 & 11.56 \\
\hline & 53.2 & 58.5 & 33.3 & 84.66 & 14.16 & 6.2 \\
\hline & 36.6 & 56.6 & 29.68 & 65.56 & 8.78 & 3.84 \\
\hline & 22.5 & 55.8 & 50.54 & 63.65 & 4.03 & 1.76 \\
\hline & 12.7 & 55.1 & 51 & 58.94 & 2.22 & 0.97 \\
\hline
\end{tabular}

When we take the maximum load of size 1280 bytes and then observe the power usage of different switches. That response has also been recorded in the form of table. Table 3 shows the statistical data when we have load of approximately 1280 bytes.

Table 3.Power Profiles of Switches with Maximum Load Size 1280 Bytes

\begin{tabular}{|c|c|c|c|c|c|c|}
\hline SWITCH & $\begin{array}{l}\text { LOAD } \\
\text { (Mbps) }\end{array}$ & $\begin{array}{l}\text { AVG } \\
\text { POWER } \\
\text { (WATTS) }\end{array}$ & $\begin{array}{l}\text { MIN } \\
\text { POWER } \\
\text { (WATTS) }\end{array}$ & $\begin{array}{l}\text { MAX } \\
\text { POWER } \\
\text { (WATTS) }\end{array}$ & $\begin{array}{l}\text { STANDARD } \\
\text { DEVIATION }\end{array}$ & $\begin{array}{l}\text { CONFID } \\
\text { ENCE } \\
\text { INTERV } \\
\text { AL }(95 \%)\end{array}$ \\
\hline \multirow{5}{*}{$\begin{array}{l}\text { CISCO } \\
2950\end{array}$} & $\begin{array}{l}84.6 \\
\end{array}$ & \begin{tabular}{ll|}
68.4 \\
\end{tabular} & 37.73 & 89.66 & 14.73 & 6.45 \\
\hline & 46.3 & 63.8 & 38.46 & 85.6 & 11.87 & 5.20 \\
\hline & 31.9 & 62.6 & 50.83 & 73.08 & 5.59 & 2.45 \\
\hline & 19.6 & 62.4 & 55.66 & 72.31 & 3.79 & 1.66 \\
\hline & 11.1 & 62.2 & 57.75 & 69.72 & 3.32 & 1.45 \\
\hline \multirow{5}{*}{$\begin{array}{l}\text { CISCO } \\
3560\end{array}$} & 84.6 & 68.0 & 50.15 & 89.4 & 11.05 & 4.84 \\
\hline & 46.3 & 67.7 & 47.68 & 95.93 & 11.02 & 4.83 \\
\hline & 31.9 & 63.3 & 52.76 & 72.46 & 6.05 & 2.65 \\
\hline & 19.6 & 61.7 & 51.15 & 70.28 & 5.03 & 2.20 \\
\hline & 11.1 & 61.6 & 57.04 & 65.15 & 2.21 & 0.97 \\
\hline \multirow{5}{*}{$\begin{array}{l}\text { NETGE } \\
\text { AR GS } \\
724 \mathrm{~T}\end{array}$} & 84.6 & 61.4 & 15.4 & 100.2 & 20.89 & 9.15 \\
\hline & 46.3 & 59.6 & 26.93 & 89.53 & 14.81 & 6.49 \\
\hline & 31.9 & 56.3 & 43.56 & 75.44 & 7.66 & 3.35 \\
\hline & 19.6 & 55.0 & 49.42 & 62.33 & 3.82 & 1.67 \\
\hline & 11.1 & 54.8 & 50.25 & 60.31 & 2.64 & 1.15 \\
\hline
\end{tabular}

\subsection{Proposed Power Consumption Model}

Statistical data shows the impact of parameter i.e. traffic load on three different switches relating to power consumption. We have collected the overall insight from previous results and proposed a theoretical model for power consumption under different scenarios. Our proposed model is versatile as compared to other previous works done in [11] [12]. So, power consumed by any switch is equal to the sum of Pbaseand Pparameters which can be written as follows.

Pswitch = Pbase + Pparameters (5)

Where Pbase represents the power consumed by the switch when none of its ports is active. On the other hand, Pparameters represents power consumed by switch when different parameters have been checked under a load environment. Above equation can be written in other form as well.

Pswitch $=$ Pbase + Pports $(6)$

Pports means power consumed by switch using active static ports and dynamic ports. Therefore, above equation can be rewritten as follows.

Pswitch $=$ Pbase $+\sum$ Piports (7)

As it has been observed that power consumption by switch does not only depend on 
ports but on packet rate as well. Suppose, Packet Transmit Time $=\mathrm{L} / \mathrm{C}$ and Packet Rate $=1 /(\mathrm{L} / \mathrm{C})$. Lastly, important parameters for power consumption of switches are taken into account and final formula is generated, where $\mathrm{f}\{$ Packetrate $\times \mathrm{L} \times 8\} \quad$ is a function that generates load when we use various parameters in different scenarios.

Pswitch $=$ Pbase + Pparametersf $\{$ Packetrate $\times \mathrm{L}$ $\times 8\}(8)$

\section{CONCLUSION}

Experiments performed initially have shown that there will be less power variation at the maximum time interval. In our research paper, clearly it can be seen that power variation of different switches is minimum when the time interval is 210 seconds. Another experiment also conducted with respect to a unit called packet rate to find the power consumption of different switches. These experiments have shown that power utilization increases with the increase in load value and packet rate value. From all experiments it is observed that the switch named Netgear GS 724T has minimum power usage under all scenarios and it outclasses other two switches.

\section{FUTURE WORK}

In this research paper we have tried our best to profile the power usage of different network switches by conducting various experiments with different scenarios. We have proposed a different and unique theoretical model for finding the power consumption of different network components. Moreover, our model will help to save energy in a communication network. Because power/energy saving will be a great achievement in any case. In future, this model can be enhanced to a later version with more amendments and can be used on complex scenarios having variable traffic patterns. Our model will help to have some research on the upper layer traffic properties as well. Also, this theoretical model will open a way to do power profiling of routers and other computer components/devices.

\section{References}

[1] J. ArjonaAroca, A. Chatzipapas, A. Fernández Anta, and V. Mancuso, "A measurement-based analysis of theEnergy consumption of data center servers," pp. 63-74, ACM Press, 2014.

[2] M. Pedram, "Energy-Efficient Datacenters," IEEE Transactions on Computer-Aided Design of Integrated Circuits and Systems, vol. 31, pp. 1465-1484, Oct. 2012.

[3] H. Kameda, E. Z. Fathy, I. Ryu, and J. Li, "A Performance comparison of dynamic vs. static load balancing policies in a mainframe-personal computer network model," in Decision and Control, 2000. Proceedings of the 39th IEEE Conference on, vol. 2, pp. 1415 - 1420, IEEE, 2000.

[4] E. Granell, S. Andrade-Morelli, E. RuizSanchez and J. Lloret,

"Energy consumption study of network access switches toEnhance energy distribution," in 2012 IEEE GlobecomWorkshops, pp. 14961501, Dec. 2012.

[5] R. Lent, "A sensor network to profile the electrical power consumption of computer networks," in 2010 IEEE Globecom Workshops, pp. 1433-1437, Dec. 2010.

[6] E. Jagroep, J.M.E.M. van der Werf, S. Jansen, M. Ferreira, and J. Visser, "Profiling energy profilers," pp. 2198-2203, ACM Press, 2015.

[7] C. Lange, D. Kosiankowski, R. Weidmann, and A. Gladisch, "Energy Consumption of Telecommunication Networks and Related Improvement Options," IEEE Journal of Selected Topics in Quantum Electronics, vol. 17, pp. 285-295, Mar. 2011.

[8] M. Gupta, S. Grover and S. Singh, "A feasibility study for power management in LAN switches," in Network Protocols, 2004. ICNP 2004. Proceedings of the 12 th IEEE International Conference on, pp. 361-371, IEEE, 2004.

[9] P. Mahadevan, P. Sharma, S. Banerjee, and P. Ranganathan, "A power benchmarking framework for network devices," in International Conference on Research in Networking, pp. 795-808, Springer, 2009.

[10] M. Colmant, M. Kurpicz, P. Felber, L. Huertas, R. Rouvoy, and A. Sobe, "BitWatts: a process-level power monitoring middleware," in Proceedings of the Posters \& Demos Session, pp. 41-42, ACM, 2014.

[11] M.A. Marsan, A.F. Anta, V. Mancuso, B. Rengarajan, P.R. Vasallo and G. Rizzo, "A Simple Analytical Model for Energy Efficient Ethernet," IEEE Communications Letters, vol. 15, pp. 773-775, July 2011.

[12] S. Herreria-Alonso, M. Rodriguez-Perez, M. Fernandez-Veiga, and C. Lopez-Garcia, "How efficient is energy-efficient ethernet?" in 2011 3rd International Congress on UltraModern Telecommunications and Control Systems, pp. 1-7, Oct 2011. 